\title{
Imágenes del mundo, imágenes en el mundo: del archivo a los repertorios visuales
}

\author{
Images of the world, images \\ in the world: from files \\ to visual repertoires
}

\author{
Gisela Cánepa (Perú) \\ gcanepa@pucp.edu.pe \\ Pontificia Universidad Católica del Perú
}

\section{Resumen}

Esta investigación reflexiona sobre la imagen como un artefacto cultural que interviene y edita la realidad. Basada en fuentes científicas, muestra la capacidad de producir actos, siempre de manera objetiva frente a una situación, para lograr como resultado un significado que deriva de su contexto. Asimismo, el paso de la imagen por la era moderna y posmoderna deja clara la llegada de las tecnologías y el cambio del hombre, que pasa a ser un sujeto que está para hacer acto de representación en el mundo. Por

\section{Abstract}

This research reflects on the image as a cultural artifact which affects and edits reality. Based on scientific sources, it displays the ability to produce actions, always objectively within a situation, to achieve a results in the form of a meaning which derives from its context. Also, the passage of the image through modern and postmodern times evidences the advent of technologies and the changing of man, who turns out to be the subject who makes representations in the world. On the other hand, it points out to the
FECHA DE RECEPCIÓN: FECHA DE REVISIÓN: APROBACIÓN:
6 de febrero de 2013

18 de febrero de 2013

12 de abril de 2013
Para Citar este artículo / to Cite this ARTicle Cánepa, G. (2013). Imágenes del mundo, imágenes en el mundo: del archivo a los repertorios visuales. Poliantea, IX (16), pp. 179-207. 
otra parte, se señala la transformación del uso o significado de la imagen que, en la actualidad, concluye en un acto de mercadeo y poder social. Y para finalizar, surge el concepto de vigilancia a través de las imágenes, concepto que utiliza el Estado para ejercer control sobre el público.

Palabras clave: imagen, cultura, representación, mundo. transformation of the use or meaning of the image that currently ends in an act of marketing and social power. And finally, there is the concept of surveillance through images, a concept used by the State to exercise control over the public.

Keywords: image, culture, representation, world. 


\title{
Imágenes del mundo, imágenes en el mundo: del archivo a los repertorios visuales
}

\author{
Gisela Cónepa (Perú) \\ Ph. D. en Antropología, University of Chicago. Coordinadora de la Maestría en Antropo- \\ logía Visual, Escuela de Posgrado, Pontificia Universidad Católica del Perú.
}

\section{Introducción}

Me propongo en este artículo presentar algunas reflexiones sobre la imagen, con el fin de plantear un argumento acerca del lugar de esta en el mundo actual, así como proponer algunas preguntas clave para una posible agenda de investigación. Mi exposición tendrá dos partes. Una primera en la que presentaré algunas consideraciones previas de orden conceptual en torno a la imagen, ya que mi reflexión se inscribe dentro de la tradición antropológica. Como se verá, estas consideraciones se desprenden de la conceptualización de la imagen como un hecho social.

\section{Modernidad /posmodernidad \\ Archivo/repertorio \\ Participar/dosificar \\ Representar/actuar \\ Eficiencia/verdad \\ Función \\ Función \\ referencial/performativa}

En la segunda parte, expondré mi argumento principal, según el cual las definiciones y usos de la imagen estarían respondiendo al tránsito de un 
modelo representacional a uno performativo, y que, por ende, exigen un giro en la manera de abordar la imagen. Mientras que en la modernidad la imagen habría estado predominantemente al servicio de la objetivación del mundo y, por consiguiente, vinculada a la institución moderna del archivo, en la era posmoderna las imágenes, más bien, tendrían sentido como repertorios que facilitaran una intervención sostenida en el mundo que respondiera al imperativo de la participación. Tal situación requiere, por lo tanto, introducir un enfoque que tome en cuenta la función performativa de la imagen, un aspecto dejado de lado por los enfoques representacionales que han dominado el pensamiento moderno.

Con el fin de explicar las particularidades de la imagen y la visión en ambos contextos, divido esta segunda parte de mi presentación en dos secciones. En la primera, me ocuparé de la relación entre modernidad e imagen, mientras que en la segunda exploraré la relación entre representación, vigilancia y performance. Finalmente, concluiré mi reflexión con algunas preguntas que considero relevantes para pensar una agenda de investigación sobre la imagen en la actualidad.

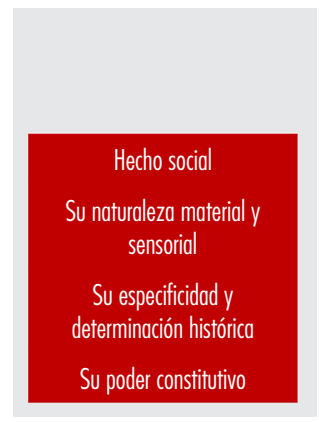

\section{La imagen como hecho social}

Como hecho social, la imagen requiere de la consideración de los siguientes puntos.

Las imágenes visuales se encuentran en la mayoría de los casos inscritas sobre materiales de distintos tipos: piedra, madera, huesos, lienzos, telas, papel o piel y, por lo tanto, son parte constitutiva de entidades que pueden ser transportables o no: muros, banderas, vasijas, cuadros, libros, cuerpos. Es necesario, entonces, reconocerles su materialidad y sensorialidad. En ese sentido, $\mathrm{y}$ aunque se tienden a atribuirle un halo de virtualidad a la imagen digital, tampoco esta se encuentra exenta de tales características: la imagen digital se proyecta sobre el monitor de la computadora o en una pantalla que, como la del iPhone, responde al calor del tacto. Con la tecnología digital la transportabilidad y replicabilidad de las imágenes se ha 
modificado enormemente, pero esta no deja de requerir de un soporte y de apelar a la sensorialidad.

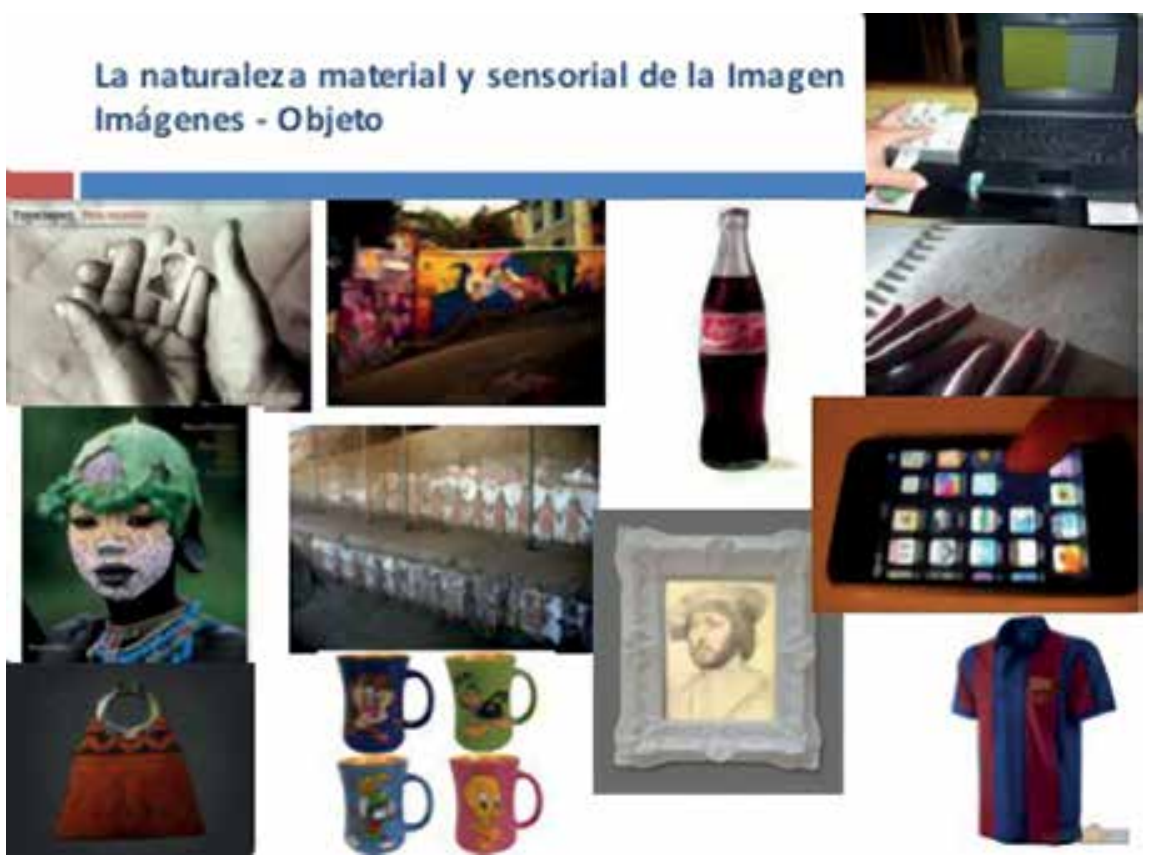

Figura 1. Naturaleza material y sensorial de la imagen-imágenes objeto.

Visto así, la imagen compromete, al menos, el sentido de la vista y del tacto, de modo que a través de la interacción cotidiana con imágenes objeto de distinto tipo se van estructurando los sentidos $y$, con ello, la manera de experimentar y de aprehender el mundo. Murales, vasijas o tejidos con diseños en relieve, aunque más claramente la escritura braille es otra expresión de esta compleja relación entre lo visual y lo táctil. Por otro lado, los programas de computador para ciegos hacen uso del sonido convirtiendo, a través de una suerte de traducción de los sentidos, un dispositivo cuyo funcionamiento está basado, eminentemente, en la interacción visual, en una herramienta útil para alguien que no ve. Se puede argumentar, entonces, que cuando se piensa en imágenes visuales no se puede reducir la comprensión de estas al sentido de la vista, menos aun cuando los desarrollos tecnológicos 
facilitan la interacción compleja entre visión, oído y tacto.

Hay ciertamente un ámbito en el cual la imagen carece de materialidad en el sentido expuesto, y este es el de los sueños y las visiones. Sin embargo, la necesidad humana de comunicarlas obliga a replicar esas imágenes en soportes que las hagan visibles a otros, que permita conservarlas o intercambiarlas. No se puede dejar de señalar, por lo tanto, que la imagen plantea el asunto de la experimentación sensorial del mundo, así como el asunto del placer. En ambos casos, la imagen media el modo en que experiencia y placer son socialmente diseñados. En ese sentido, me inclino a entender la imagen como un artefacto cultural y no únicamente como un texto cultural, ya que el sustantivo artefacto rescata la idea de manufactura y de materialidad.

Las imágenes son construcciones sociales y, por ende, responden a especificidades históricas y culturales, mientras que sus significados y valoraciones están contextualmente determinados. La valoración diferenciada de imágenes visuales distintas en épocas históricas particulares y según culturas específicas ha sido ampliamente documentada. Así, en el siglo XVI un retrato pictórico era admitido como evidencia para alegar por derechos de filiación. En los siglos XIX y XX, fue la precisión de la tecnología fotográfica la que otorgaba rango de objetividad a un registro visual. En la actualidad, se ha pasado más bien a identificar la tecnología con la posibilidad de intervenir y editar la realidad. A mayor sofisticación tecnológica, mayor posibilidad de manipulación y, por consiguiente, menor certeza sobre la autenticidad de un registro. Esto puede explicar el alto nivel de credibilidad atribuido al registro de sucesos en videocámaras o incluso celulares.

Si bien son registros de baja calidad y con un juego de cámara confuso, se tiene la idea de que se trata de un registro verídico, legitimado en realidad por la idea que la cámara estuvo allí, que fue testigo de los acontecimientos. Basta ver el éxito que tienen las convocatorias de medios de comunicación para que los ciudadanos de a pie envíen sus registros en video, que si bien no alcanzan los estándares de calidad para la emisión por televisión, hoy son emitidos como materiales con valor testimonial o, eventualmente, usados como evidencia en casos de violación de derechos. 
No hay nada intrínseco en la imagen que dé cuenta de la veracidad de lo que ella registra. Es a través de las convenciones de los géneros audiovisuales, como el documental o la ficción, y del juicio de los expertos, que se atribuye valor representacional a la imagen. Existe, pues, siempre un marco discursivo y de acción que define los usos, lecturas y apropiaciones posibles de una imagen. En ese sentido, su estudio no puede prescindir de la consideración de las instituciones, procesos productivos y tecnológicos e historias sociales que las configuran. Me he ocupado acá de aspectos vinculados a la objetividad de la imagen, pero lo mismo vale para sus implicancias políticas y éticas.

A modo de ejemplo, presento unas imágenes que fueron registradas por la cámara de uno de los periodistas muertos en Uchuraccay durante el conflicto armado, el 26 de enero de 1983, cuando un grupo de ocho periodistas realizaron una expedición a una de las comunidades que se encontraba en la zona de conflicto. Desde entonces, las fotos han circulado en distintos medios, como periódicos, televisión, muestras fotográficas del conflicto, libros e Internet.

\section{Especificidad y determinación histórica y contextual}

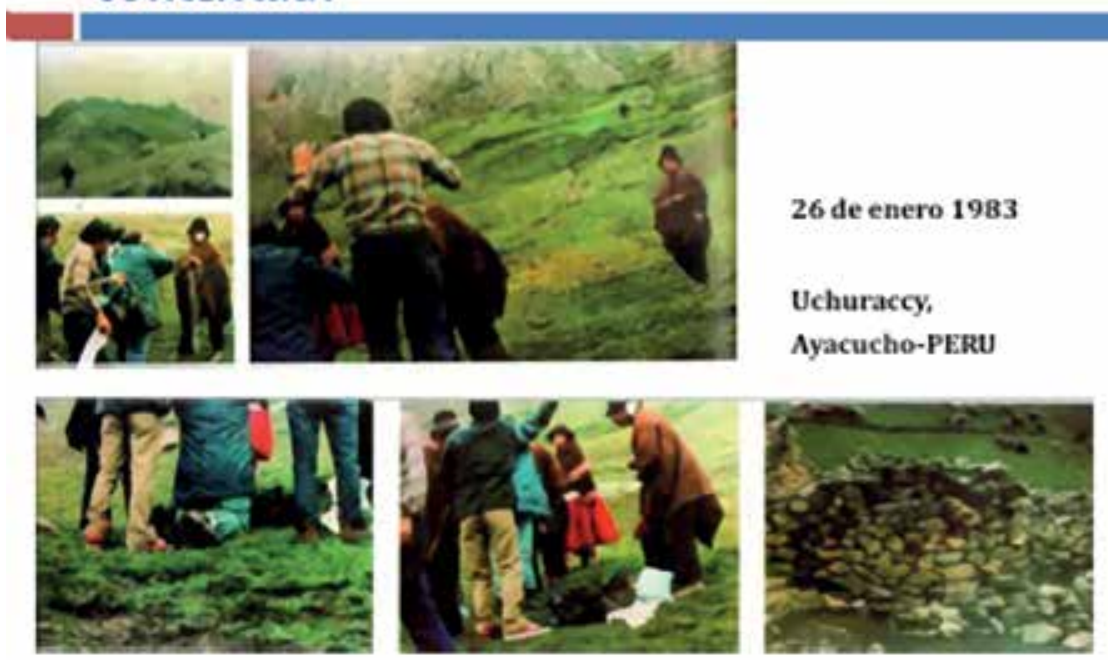

Figura 2. Especificidad y determinación histórica y contextual. Uchuraccy (Ayacucho, Perú). 
Las fotografías no contienen evidencia que ayude a esclarecer los hechos. En realidad, solo contienen el testimonio de que la cámara estuvo allí y de que su dueño trató, sin éxito, de registrar lo que sucedía. Debe ser la certeza de la presencia de la cámara en medio de lo que ocurría lo que le da legitimidad a las fotografías como evidencia de lo sucedido y que se las interprete en esos términos. $\mathrm{Y}$ en este ejercicio, lo que ha ocurrido es que estas se han interpretado a partir de algunos índices, como el paisaje andino, las construcciones de piedra y la indumentaria propia del indígena que contrastan con las ropas urbanas y el equipo fotográfico de los periodistas, para concluir que la fatalidad de lo ocurrido se debió a un problema de comunicación, a un asunto de desencuentro cultural.

Pero si las imágenes realmente no contienen evidencia de lo ocurrido, entonces ¿qué legitima la lectura que se hace de ellas? Por un lado, está el informe de la Comisión Investigadora integrada por expertos antropólogos y la voz autorizada del escritor Vargas Llosa como figura pública. Por el otro, el argumento culturalista de la matanza se sustenta en una narrativa nacional en la que el indígena campesino y la sociedad andina son la expresión de la barbarie y del retraso; en otras palabras, ambos encarnan aquella otredad que hace imposible el proyecto nacional. El ejercicio de interpretación de estas fotografías ha terminado reproduciendo una compleja historia de exclusión social y cultural, así como ocultando el contenido político del conflicto armado que el Perú vivió en las dos últimas décadas del siglo XX! .

Ejemplos como estos señalan los límites de situar la discusión respecto de la objetividad o verdad de una imagen. Tal planteamiento resulta problemático, ya que oculta el carácter construido de esta. La pregunta más bien debe ser: ¿cómo es que se construye y legitima la objetividad y el valor de verdad atribuido a una imagen? ¿Por qué los peruanos leen estas fotos como la evidencia de un desencuentro cultural?

La contraparte de lo dicho implica que los sujetos aprenden a leer las imágenes en la clave que el contexto social dicta. Como construcciones sociales, las imágenes no solo construyen el mundo que

Una discusión interesante sobre los aspectos aquí señalados se encuentra en Poole y Rojas (en prensa). 
representan, sino también a los sujetos que lo interpretan. En otras palabras, las imágenes no simplemente reflejan la realidad, sino que son constitutivas de estas en el sentido que moldean la mirada, construyen el sujeto que mira y se realizan según cánones estéticos o de verdad legitimados socialmente.

\section{El poder constitutivo de la imagen}
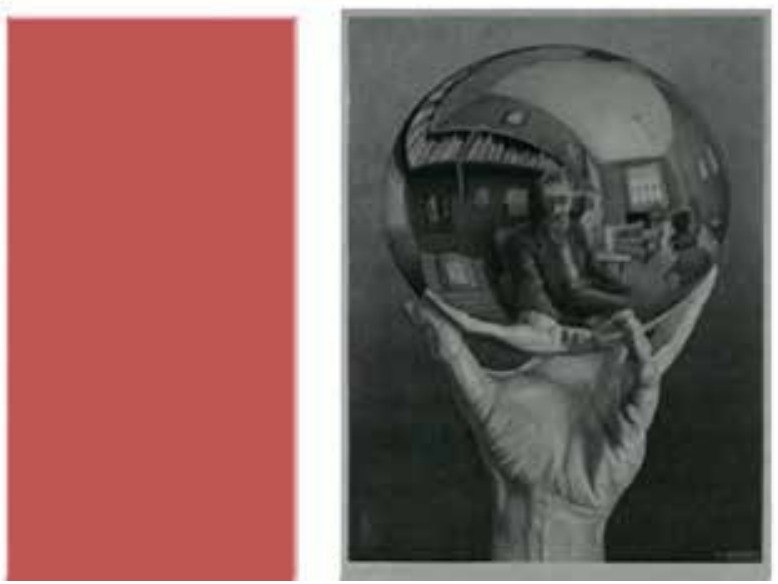

Figura 3. El poder constitutivo de la imagen

Siguiendo el planteamiento de funciones representacional y perla imagen como un hecho social y formativa a las que responde. reconociéndole poder constitutivo, considero que la pregunta pertinente para organizar conceptual y metodológicamente su estudio es la siguiente: ¿qué es lo que la imagen hace? Al mismo tiempo, el estudio de la imagen requiere tomar en cuenta, al menos, los siguientes aspectos que la constituyen: su condición de objeto, la tecnología que la hace posible y condiciona y las
Ya he comentado acerca de la condición de objeto de la imagen, y esta consideración implica pensar su producción, circulación y consumo, siempre dentro de un sistema productivo específico. La imagen es, pues, constitutiva de relaciones sociales en el sentido de que su producción implica alguna forma de división de trabajo, mientras que su circulación crea relaciones de reciprocidad, 
jerarquía, dependencia y lealtad, y interpretaciones, a sentidos de idensu consumo da lugar a usos parti- tificación y a apropiaciones.

culares, a la asignación de valor, a

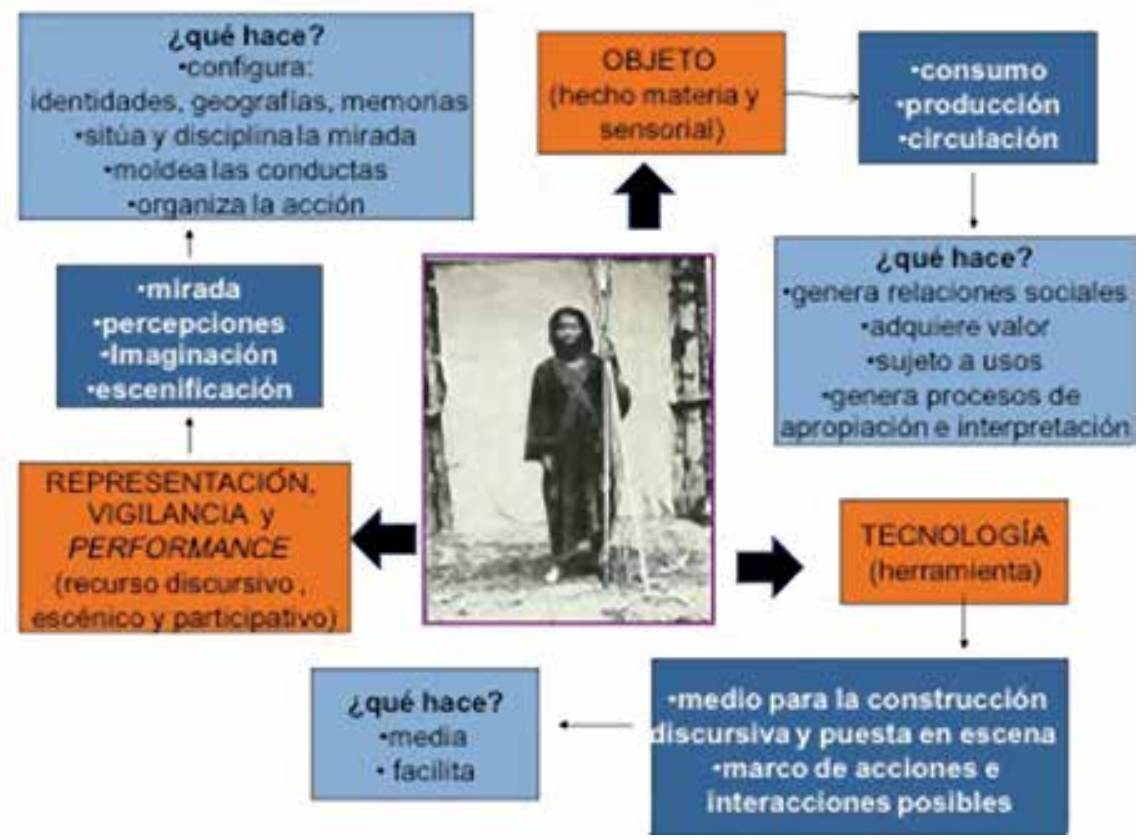

Figura 4. La imagen: constitutiva de relaciones sociales

La tecnología que la hace posible es, al mismo tiempo, central en la definición de los marcos de acción e interacción posibles. Por lo tanto, la tecnología facilita, pero también media la producción de significados, así como las relaciones sociales. La tecnología es, pues, también un fenómeno social. Siguiendo a Poole (2000) cuando en 1854 AndréAdolphe-Eugène Disdéri patentó un nuevo formato fotográfico para retratos de $6 \times 10 \mathrm{~cm}$, creó un objeto fácil de transportar, intercambiar y coleccionar, así como factible de ser producido masivamente y adquirido a un bajo costo. La tecnología, pero también los usos sociales que se le dio, estuvieron al servicio de la creación de un objeto totalmente coherente con las lógicas de producción, circulación y consumo del sistema capitalista.

Este nuevo formato, llamado tarjeta de visita o tarjeta álbum, contenía, en un primer momento, 
retratos de la burguesía y luego de tipos humanos, escenas costumbristas, monumentos y paisajes del mundo. En el contexto del sistema capitalista, las tarjetas de visita no solo fueron valoradas respecto de su valor de uso - como tecnología representacional-, sino, sobre todo, en cuanto a su valor de cambio. Las tarjetas de visita pasaron a ser usadas como objetos de intercambio recíproco en interacciones sociales ritualizadas, se coleccionaban en álbumes y se acumulaban como capital social. En todos estos casos, las tarjetas de visita mediaron relaciones sociales y se constituyeron en marcadores de clase.

La fotografía analógica y sus posibilidades de reproducción introdujeron cambios importantes que, por ejemplo, retaron la noción de autenticidad y originalidad de la obra de arte. La fotografía digital, por su lado, está contribuyendo a cambiar la lógica de acumulación y colección vinculada a la foto analógica. En la actualidad, lo que se valora y opera es la conectividad y simultaneidad: la imagen fotográfica que media dentro de una red de relaciones sociales y facilita la acción. Facebook es, ciertamente, una clara manifestación de lo dicho, pero véase a modo de ejemplo una escena de la serie CSI New York (http:// www.youtube.com/watch? $\mathrm{v}=\mathrm{blCBY}$ F9Fbv4\&feature=related).

Las escenas de la serie CSI New York corresponden al capítulo titulado Redemption (temporada 6, episodio 19). Uno de los agentes del equipo de investigación se ve atrapado en una cárcel durante una revuelta de los internos. Con su celular toma una serie de fotografías que envía inmediatamente a sus colegas que se encuentran en los laboratorios de investigación. Estas fotografías, junto con el material fotográfico y visual, como planos del penal, son las que desencadenan una serie de acciones que definen la secuencia de la narración. Las imágenes que circulan por Internet, que aparecen en pantallas táctiles y que son manipuladas, permiten explicar los acontecimientos detrás del motín, así como instruir al compañero sobre cómo debe desplazarse por el edificio para mantenerse a salvo hasta que el local sea recuperado por la Policía. Este material visual no solo está allí para ser visto e interpretado. Lo que lo caracteriza es más bien su capacidad de producir actos, que comprenden desde la manipulación del propio material 
visual hasta la intervención en los sucesos mismos. Finalmente, hay que destacar que, a través del propio lenguaje, estética y ritmo de la edición, se expresa la naturaleza performática de las imágenes.

La consideración de la tecnología es fundamental para abordar la imagen como un hecho social, pero también es una entrada clave para prestar atención a los cambios que están ocurriendo y que configuran nuevas definiciones y usos de la imagen. Las escenas televisivas a las que he hecho alusión son ilustrativas de los cambios que se están dando y a los que se debe prestar atención.

Si bien me he preocupado por resaltar los aspectos materiales, sensoriales y tecnológicos que la constituyen, la imagen es también representación. En este sentido, ella sitúa y disciplina la mirada $y$, con ello, moldea los modos de percibir, imaginar y experimentar el mundo. De esta manera, la imagen ha desempeñado un papel central en la configuración de identidades, lugares y memorias. Pero la imagen también es un instrumento para moldear la conducta, organizar la acción e intervenir en el mundo. Ella puede ser asimismo un evento. Mi propuesta es, entonces, abordar el estudio de la imagen y comprender su papel en la constitución del mundo social, considerando su función referencial (representacional) y su función performativa (escénica).

Siguiendo con el enfoque propuesto y para avanzar en mi argumento, es necesario empezar por presentar los marcos discursivos y de acción dentro de los cuales estas funciones se llevan cabo, encuentran su sentido y logran eficacia. Por lo tanto, empezaré por situar la imagen primero en el contexto de la modernidad y en un segundo momento en el contexto de la posmodernidad. Ese orden me permitirá, además, argumentar que el énfasis puesto en lo referencial como enfoque que ha dominado el estudio de la imagen se explica por el modo en que opera la imagen y la visión en el contexto de la modernidad.

\section{La conquista del mundo como imagen}

Martin Heidegger en su ensayo sobre ciencia y modernidad afirma: "El proceso fundamental de la Edad Moderna es la conquista del mundo como imagen" (1960). Para él, el tránsito hacia la modernidad conlleva un cambio de la relación del hombre con el mundo. Mientras 
que antes el mundo se presentaba o revelaba ante el hombre y, por lo tanto, existía independientemente de él, en la modernidad el mundo es descubierto por el hombre y representado por él. En otras palabras, el mundo se empieza a comprender como imagen, al tiempo que adquiere existencia a través del hombre, con lo cual este se constituye en la medida de todas las cosas.

En esta línea de argumentación, se observan cuatro procesos relacionados entre sí que la modernidad trae consigo.

Dichos procesos, a su vez, van a impactar y ser impactados por 1) el lugar que la visión adquiere como instrumento de conocimiento; 2) la relación que guarda la visión con otros sentidos y el modo en que se estructura la percepción sensorial del mundo; 3) los usos que toman los recursos visuales tanto de carácter expresivo como tecnológico, y 4) la dirección en la cual se disciplina la mirada y se constituye la persona.

En la medida en que lo existente se define como representación, el mundo es lo que se representa y, por ende, solo aquello que se constituye en objeto de representación adquiere existencia. A su vez, el proceso de objetivación del mundo es también el proceso por el cual emerge el sujeto de lo existente, es decir, aquel que pone el mundo ante sí. En este escenario, se vislumbra ya la posición de poder que adquiere el hombre en cuanto representante de lo existente. Por el contrario, el objeto se encuentra desprovisto de poder, ya que no es quien marca la medida de la imagen que el mirar del sujeto instituye.

En la era moderna, el desenvolvimiento de la humanidad responde al mandato de garantizar al hombre la condición de sujeto. Por ende, la modernidad impone sobre el sujeto la necesidad de involucrarse en la lucha por la representación. En ese sentido, el representar se constituye en un acto histórico y político. Siguiendo esta línea de argumentación, el proyecto moderno debe entenderse como la historia de la lucha por mantener la posición de sujeto, es decir, la historia de la lucha por la representación.

A lo largo de la historia, el hombre ha estado abocado a representar el mundo a través de distintos medios. Lo que otorga especificidad a la representación en el contexto de la modernidad es que esta instituye un orden en el cual la objetividad se erige como horizonte con respecto 
al cual se establece la verdad en el ámbito del saber y la legitimidad en el ámbito del poder.

Como se desprende del argumento de Heidegger (1960), la objetividad constituye un tipo de relación entre sujeto y objeto y, por consiguiente, se requiere de un método que 1) establezca los términos de tal relación, 2) defina las unidades de representación del objeto y 3) discipline la mirada del sujeto representador. Es el método científico, que basa precisamente su principio de verdad en la objetividad, el que ofrece los instrumentos para configurar esta forma particular de conocimiento y de instalarse en el mundo. De este modo, la ciencia moderna se convierte en el medio a través del cual el hombre refuerza su condición de sujeto y garantiza su primacía sobre la naturaleza. Ella es la respuesta que el hombre ha encontrado al imperativo que la modernidad le impone.

La constitución del mundo como imagen pasa por la necesidad de conformar el mundo de acuerdo con unidades de observación, descripción, análisis y comunicación que fueran comparables entre sí, al mismo tiempo que intercambiables. De tal modo, se asume a un sujeto diverso y móvil, pero entrenado en la identificación de unidades discretas y unívocas. En lo que concierne al sentido de la vista, tal aproximación al mundo requirió de un particular dominio y disciplinamiento de lo visual, de modo que el sentido de la visión pudiera funcionar como una legítima herramienta de conocimiento objetivo.

El gran cambio epistemológico del siglo XIX responde a este precepto del "mundo como imagen", dando lugar al surgimiento de la noción de tipo como una unidad de representación fundamental, tanto en las ciencias naturales como en las ciencias humanas.

Como explica Poole (2000), hasta ese momento el paisaje se definía, principalmente, a través de características, como la temperatura y la humedad. Por lo tanto, la diferencia se percibía a través del sentido del tacto y se expresaba en cuanto a la cercanía o lejanía con respecto a un centro, que daba lugar al modelo de círculos concéntricos desarrollado por el conde de Buffon. El gran aporte de Alexander von Humboldt a la geografía como ciencia moderna fue, precisamente, reemplazar el enfoque táctil por uno visual. En su propuesta, las diferencias en 
el paisaje no se hacen perceptibles a través de sus características táctiles, sino más bien por medio de sus formas visuales y estéticas. En otras palabras, lo que propone Humboldt es descifrar el carácter visual de una región. Tomando en consideración la subjetividad del observador, la tarea implicará, entonces, una serie de procedimientos que consisten en 1) separar la visón de los otros sentidos, 2) disciplinar la visión para detectar las diferencias visuales - fisiognómicas - del paisaje y 3) conformarlas en una serie de imágenes visualmente discretas, posibles de ser registradas, acumuladas, archivadas, intercambiadas y comparadas.

De esta manera, Humboldt introduce una lógica de espacialización y tipologización en el modo de estructurar la apreciación y comunicación del paisaje. Su "método visual" resultará fructífero en otras disciplinas, ya que más allá de tomar nota de características externas constituye una manera de organizar la mirada de acuerdo con unidades discretas que pudieran ser descritas, clasificadas y comparadas. Así es como este mismo principio podía ser aplicado a la consideración de características que no fueran apreciables a simple vista, como en la zoología y la anatomía.

Con esta lógica de espacialización y tipologización, se termina por generar un nuevo sentido acerca de lo que constituían el conocimiento y el ámbito de lo visual, al mismo tiempo que el sentido de la vista adquiere hegemonía como recurso para lograr un conocimiento verdadero. Junto con el desarrollo del método visual se desarrollan instrumentos de registro, medición y presentación con los que se buscaba optimizar el desempeño de la visión, como el microscopio, la fotografía, los mapas, los cuadros estadísticos, etcétera.

Siguiendo la línea de argumentación aquí presentada, se puede afirmar que los términos con que la ciencia define el principio de objetividad implica una organización de la mirada que pone a mirar el centro, es decir, el mirar como la relación primordial con el mundo. Se instituye el mirar como un acto de poder. Dentro de esta misma línea de reflexión, se ubica el argumento según el cual en la modernidad el mundo deviene espectáculo (Debord, 1976). Los usos, así como las formas expresivas, basadas en los recursos que nos ofrecen las tecnologías de 
la comunicación audiovisual, funcionan todos dentro de los marcos establecidos por este orden representacional y sus mandatos.

Esto puede ayudar a explicar el hecho de que la subjetividad moderna se encuentre marcada por la tensión entre el placer de mirar y el placer de ser visto. El sujeto tiene, por ende, una doble consciencia: la de ser visto y la de ver que es visto. La expresión más acabada de la condición moderna es aquella expresada por Lacan (citado por Mirzoeff, 1998, p. 11) en la figura del sujeto que se ve mirándose a sí mismo, mientras que para Mirzoeff (1998), la narrativa moderna es una en la que el sujeto se constituye en el foco de un drama panóptico de identidad. Esta figura paradójica de ser sujeto y objeto de representación y vigilancia a la vez es ciertamente coherente con la manera en que Foucault (1990) explica que opera el poder en la modernidad.

Se nos develan, así, dos funciones constitutivas de la imagen en la modernidad: representar y vigilar. Mientras que para la primera entra en juego el método científico, con su poder de objetivación según criterios clasificatorios, para la segunda funciona el panóptico que ejerce un poder disciplinario que actúa sobre la conducta. Quiere decir que la relación entre imagen y poder se juega en dos ámbitos: en el de la lucha por quién representa a quién y en el de la lucha por quién vigila a quién. Como discutiré a continuación, el dominio de la mirada no solo es central para alcanzar un conocimiento verdadero, sino también para ejercer un dominio legítimo.

En su estudio sobre fotografía y raza en los Andes, Poole (2000) discute la importancia que tiene el método visual en el desarrollo del concepto moderno de raza. Hasta antes del siglo XIX lo que unía a una raza o a una nación era algo intangible y no algún elemento de similitud visual o fisiológica. La raza se definía por sucesión, es decir, por vínculos genealógicos y no por características tipológicas. En los campos de la criminalística, la fisiognomía y la antropología física del siglo XVIII se había avanzado ya en desarrollar una serie de convenciones para llegar a un registro fotográfico que hiciera posible el trabajo de clasificación y comparación de unidades discretas, y que, consiguientemente, hiciera visible la similitud y diferencia entre individuos concretos. Estas formas de identificación y análisis 
dieron lugar a que la enorme variabilidad entre individuos particulares fuera abstraída y agrupada bajo la regularidad de un número limitado de tipos. Este modo de organizar la mirada $y$, por ende, la percepción de la diferencia humana, fue fundamental para reconceptualizarla respecto de tipos humanos. Así fue como la raza se convirtió en un problema visual a la vez que en un hecho material y, por lo tanto, biológico.

Las convenciones en el registro fotográfico desarrolladas en el ámbito científico, que ciertamente eran distintas a las de las fotos retrato de las burguesías europeas, fueron tomadas por los exploradores, viajeros y misioneros del siglo XIX para retratar la diversidad de los grupos humanos dispersos en el mundo (Flores, en prensa). Entre estos, algunos fotógrafos con objetivos comerciales produjeron materiales que circularon en publicaciones de divulgación y como postales. Estas últimas fueron adquiridas por etnólogos de la época como material de campo, así como por las élites urbanas que las coleccionaban, intercambiaban y ordenaban en álbumes fotográficos. Tal práctica social que se sustenta en una concepción archivística de la imagen fotográfica contribuyó a popularizar y a entrenarnos en los trabajos de la clasificación y comparación propios del método científico, y a disciplinar nuestra mirada para reconocer los tipos humanos como realidades objetivas. Esto sucedió hasta el punto de que tal identificación se llegó a percibir como un acto natural, que oculta su carácter social e históricamente determinado.

La fotografía, pero también el museo y los mapas difundidos a través de los textos escolares y las publicaciones de divulgación científica, ha tenido un papel fundamental en la popularización de las lógicas de la espacialización y tipologización, proyectando y transmitiendo las nociones de objetividad y visualidad señaladas, con respecto al paradigma de la ciencia moderna, a los campos social y cultural. Se trata de dispositivos visuales que han configurado no solo proyectos científicos, sino también las nociones y sentimientos de raza, nación y geografía fundamentales en la conformación de los Estados y comunidades nacionales. De este modo, han contribuido a llevar a cabo los esfuerzos de objetivación del mundo en el ámbito político. Naturalmente 
que el mercado también ha desempeñado un papel importante en este proceso, al convertir las representaciones legitimadas por la ciencia en mercancías y, por lo tanto, en objetos de consumo masivo y fuente de satisfacción y placer.

Dentro de esta línea de argumentación, representar como acto de poder se constituye en acción histórica. Como han señalado Said y Foucault sobre el proyecto colonial y el Estado moderno, respectivamente, estos han implicado la puesta en práctica de tecnologías de objetivación a través de las cuales las sociedades colonizadas se han constituido en Otro cultural. El "otro" existe en cuanto es constituido en objeto de representación. Los ejemplos abundan con respecto a los recursos visuales puestos al servicio de tal empresa, como el cine, la fotografía, los museos, las ferias mundiales. Este poder de la representación encuentra su expresión más acabada cuando el sujeto representador logra, además, definir los términos de la representación. Es decir, cuando se logra que el Otro cultural se represente a sí mismo en los términos ya definidos por la mirada hegemónica.

El tipo de problemática discutida líneas arriba está íntimamente ligada a la función referencial de la imagen, y ha dado lugar a una cantidad importante de trabajos. Incluso me animaría a afirmar que el enfoque que ha dominado el estudio de la imagen es el que privilegia la función referencial de esta, en detrimento de su función performativa. Dicho énfasis se explica precisamente por el papel que la imagen ha tomado en el contexto de la modernidad. En este, donde saber y poder se rigen por el principio de verdad, la imagen es evaluada y valorada, principalmente, respecto de su capacidad de realizar una representación verdadera del mundo. Por otro lado, hay que anotar que la identidad ha ido adquiriendo valor político en el sentido que la diferencia constituye un argumento para el reclamo de derechos (Turner, 1991). De este modo, la lucha política ha devenido en una lucha sobre la representación y visibilización de las diferencias, mientras que imagen e identidad e imagen y memoria se han constituido en los grandes campos donde se lleva a cabo esta disputa.

En esta misma línea de reflexión pueden ubicarse una serie de proyectos que han consistido en entregar la cámara fotográfica o de video a grupos indígenas, grupos 
urbanos marginales, $\mathrm{u}$ otros grupos excluidos, con el fin de otorgarles los medios para su propia representación y visibilización pública.

Tales proyectos, a su vez, han dado lugar a importantes debates, en los cuales se argumenta, por ejemplo, que el hecho de entregar la cámara no hace más que perpetuar una situación colonial en la medida en que los grupos subalternos no pueden sino representarse en los términos ya establecidos por la mirada hegemónica, haciéndose agentes de su propia exotización (Faris, 1992). En respuesta a esta posición, se argumenta que tales críticas están teñidas de nostalgia y suponen la existencia de verdades absolutas, de esencias, que en el plano de la política de las identidades se traducen en la exigencia de ser auténticos (Turner, 1996).

Tales críticas estarían enfrascadas en una discusión acerca de la verdad de la representación, es decir, acerca de su valor referencial, que impedirían ver lo que realmente está en juego. Este enfoque sería incapaz de tomar una distancia crítica del orden representacional en el cual opera la producción, la circulación y el consumo de imágenes. Por lo tanto, hace difícil entender a fondo la pragmática de la imagen, así como las posibilidades contextualmente determinadas de actuar de manera estratégica a través de ellas (Turner, 1996). Por otro lado, si es en el ejercicio de la representación que el sujeto adquiere su condición como tal, sería una imprudencia insinuar que los grupos subalternos no deban realizarlo en nombre de la autenticidad.

Un ejemplo claro de los límites de una discusión que se enfoca únicamente en el valor referencial de la imagen es el caso de los llamados vladivideos. El 14 de septiembre de 2000 salió a la luz el video KouriMontesinos, el primero de una serie de vladivideos, cuyo impacto en la opinión pública aceleró la caída del régimen fujimorista en ese mismo año. Lo que se revela sobre los vladivideos es que lo que está en disputa no es, simplemente, el valor referencial de la imagen (Cánepa, 2005).

El material difundido ofrecía la evidencia visual de los actos de corrupción del Gobierno; se podía ver, por ejemplo, al jefe del servicio de inteligencia y cómplice de Fujimori entregar dinero al dueño de un canal de TV, sin embargo, el verdadero poder de las imágenes no residía en su contenido, ya que en realidad 
hacía referencia a una realidad ampliamente conocida. No era nada novedoso lo que se mostraba en ellos ni se debatía la veracidad de las imágenes. La naturaleza de su contenido no bastaba para explicar la reacción de la gente, que empezó a salir a las calles y a reclamar la caída del régimen. La clave estaba en lo que estas imágenes hicieron, y esto fue: colocar una realidad ante la mirada. De este modo, las imágenes creaban un evento, uno en el cual se comprometía al público a tomar una posición sobre la legitimidad de la vigilancia que el Estado ejerce sobre ellos. Los vladivideos crearon una situación en la que se revertieron los términos del control.

Los sujetos de gobierno de los Estados nacionales lo son en cuanto poblaciones con identidad sobre las cuales es posible diseñar y aplicar políticas en distintos rubros: educación, salud, seguridad. El gobierno efectivo y eficiente requiere, por lo tanto, de tecnologías de objetivación que conviertan la indefinición de la masa en una realidad de unidades discretas y susceptibles de ser clasificadas. Pero, además, de tecnologías disciplinarias que regulen las conductas y hagan a los sujetos predecibles, de modo que, a su vez, actúen según las características que les han sido atribuidas en cuanto segmentos de población.

Cuando se proyectaron los videos por televisión, por un momento el Estado perdió control sobre el ejercicio exclusivo y legítimo de la vigilancia. En el contexto de la posguerra y de una dictadura de facto, este control no solo se había intensificado, sino que fue ejercido incluso atentando contra los derechos humanos. En otras palabras, lo que estaba en juego y era causa de disputa era quién podía y debía ejercer legítimamente la vigilancia. Un asunto que también está en el centro del caso de los wikileaks.

Siguiendo a Foucault (1990), el ejercicio de la vigilancia se encuentra en la intersección entre visibilidad y poder social $\mathrm{y}$, por lo tanto, es central para entender la forma en que opera el poder en la modernidad. Los Otros culturales, así como las poblaciones nacionales, son objetos susceptibles de ser contabilizados, clasificados, regulados y vigilados. La consideración del orden representacional instituido por la modernidad exige tomar en cuenta tanto las tecnologías de representación como las tecnologías de vigilancia. Además de la disputa 
sobre la representación, se da la lucha por la hegemonía de la mirada. $\mathrm{El}$ asunto ya no se reduce a construir una representación verdadera, objetiva de la realidad, sino a influir y ejercer control sobre la conducta de otros y sobre la propia. En ese sentido, el estudio de la imagen en la modernidad requiere tomar en cuenta el poder disciplinario de la imagen, es decir, considera el papel que la visión y las tecnologías visuales tienen como dispositivos de vigilancia (Mirzoeff, 1998).

En la medida en que el sujeto visual de la modernidad se sabe vigilado, la ubicación de cámaras en lugares públicos funciona como dispositivo que actúa sobre la conducta. Piénsese en cámaras de vigilancia puestas en lugares estratégicos para controlar el exceso de velocidad, en centros comerciales, ascensores, y otros lugares públicos. En muchos casos generan en nosotros seguridad; pero ¿qué sucede cuando un individuo se sabe "fuera de lugar" y sus marcas de identidad son indicadores registrables visualmente, como la ropa o el color de piel? En este caso, las cámaras de vigilancia actúan sobre la autopercepción - saberse negro, indio, árabe, latino, saberse mujer o saberse homosexual-, así como sobre la conducta (Fiske, 1998). Frente a una cámara no basta con saberse inocente, sino que se hace imperativo parecer inocente.

De este modo, la cámara de video, así como otros medios de vigilancia, como el carné de identidad, el pasaporte, la huella digital, entre otros, son dispositivos a través de los cuales se regula la conducta y se establecen fronteras espaciales que logran incluso la autoexclusión de lugares que no le son otorgados a uno como propios.

Se está, pues, aceptando con demasiada pasividad la colocación de cámaras de videos en todas partes, o nosotros mismos subiendo nuestras imágenes en Internet olvidando que son objeto de vigilancia por parte de empresas que ya acceden a la información que hay de nosotros en la web; de nosotros, de nuestros gustos, de nuestros itinerarios, de nuestras redes. Mientras que las cámaras en las calles nos vigilan en cuanto sujetos de gobierno, Google nos vigila en cuanto sujetos de consumo. La nueva tecnología ya no simplemente nos identifica como cuerpos que llevan marcas raciales, de género o de etnicidad, sino que nos rastrea como cuerpos que llevan 
señales digitales convirtiéndonos en puntos en una red o en puntos en un itinerario.

La contraparte de la vigilancia ejercida por las instituciones de gobierno es la que ejerce el transeúnte que con su teléfono celular puede registrar un incidente o la del activista que planifica su acción incluyendo la cámara como un actor. En el primer ejemplo, se generan registros que pueden ser utilizados como evidencia en casos de abuso de autoridad o violencia contra minorías. En el segundo, la presencia de la cámara interviene en el evento haciéndolo público y susceptible de juicio por terceros, e induce a las partes a actuar para ella, ya sea en una u otra dirección.

Lo que se va revelando en la actualidad es que el uso político de la imagen ya no se restringe a su función representacional - poder autorrepresentarse o hacerse visible-, sino su instrumentalización en un sentido performativo. He anotado líneas arriba que la propia tecnología digital facilita su uso en ese sentido y en distintos ámbitos de la vida social. Esto implica la posibilidad de que la imagen sea utilizada como un recurso de intervención, un medio a través del cual se participa de manera explícita y reflexiva en la producción de la realidad misma.

Es sobre esta función performativa de la imagen, aún no suficientemente tomada en cuenta por los estudios visuales, que quiero comentar a continuación. Para tal efecto, considero importante situar la imagen en un marco discursivo y de acción distinto al de la modernidad y que define el saber y poder en el orden de la posmodernidad.

\section{La imagen y el imperativo de la participación}

La posmodernidad constituye un régimen de saber y poder que opera según lo que Lyotard (1987) llama el "principio de la performatividad", donde la performance constituye un régimen de fuerza normativa que se legitima en la medida en que garantiza y da sostenibilidad a la eficiencia del sistema y su propia capacidad de transformación. En este orden caracterizado por la premisa "saber es poder", el saber, a diferencia de lo que dicta el paradigma de la modernidad, es utilizado según su potencial productivo y transformativo, y legitimado por su aplicabilidad, es decir, por su pertinencia para optimizar y dar sostenibilidad a las intervenciones en el mundo, y 
no por su capacidad de representarlo. El saber, por lo tanto, se mide respecto de la eficiencia, la eficacia y la efectividad, es decir, por su operabilidad, y no por la verdad de sus enunciados.

En tal sentido, se puede argumentar que, mientras que la episteme moderna está construida sobre los conocimientos que provienen de los discursos legislativos en el ámbito de lo penal, así como de los mecanismos de vigilancia, la episteme posmoderna se sustenta en los conocimientos que provienen de los discursos del management (administración/gerencia) social y público, así como de las metodologías participativas. Estos últimos, management y metodologías participativas, suponen un sujeto participativo, es decir, creativo, emprendedor, responsable, anhelante y expresivo. Estas cualidades constituyen, a su vez, elementos fundantes de lo que considero el ethos neoliberal, que se encuentra a su vez regido por el imperativo de la participación. Parafraseando a McKenzie (2001), este ethos dice así: "Participa o estás fuera...."

Ampliando la afirmación de Lyotard (1987), e introduciendo algunas consideraciones provenientes de los estudios de performance, propongo que el modo de operar del régimen posmoderno en el ámbito social y cultural deviene en la aplicación de estructuras dramáticas a distintos campos de la actividad humana. En otras palabras, el flujo de la vida social se hace inteligible y es normalizado a través de su dramatización, a la vez que los sujetos se convierten en actores. El sistema requiere, pues, de sujetos públicos que se destaquen por ser creativos, emprendedores, responsables, siempre dispuestos al cambio, por ende, performativos y participativos.

Dentro de tal dinámica, se observa la proliferación de repertorios que provienen de los géneros y mecanismos de las formas de la cultura expresiva, como el teatro, el ritual, la música, la danza, las peregrinaciones, los concursos, las competencias deportivas, los festivales y el circo, que se instrumentalizan en un sentido productivo y estratégico ya sea para gestionar recursos humanos y culturales, o para gobernar y producir. Estas tecnologías performativas se aplican de forma masiva, circulan como mercancías o servicios dentro del mercado, se legitiman respecto de su eficacia para generar impactos y se perfeccionan a través 
del desarrollo de saberes y campos disciplinarios que hacen posible su uso reflexivo e instrumental. La publicidad y el márquetin, así como el coaching y la gerencia social, han desarrollado una oferta de productos y programas que utilizan metodologías performativas en el sentido de que basan estas en el ensayo, la persuasión, la ritualización, la dramatización y la espectacularización, así como en el principio de responsabilidad. Estas metodologías trabajan alrededor del empoderamiento individual (reflexividad y autoconocimiento), así como de la creación de lealtades y sentidos de pertenencia, al mismo tiempo que producen sujetos eficientes para el sistema.

Asimismo, corresponden a un giro en los ámbitos de la gerencia y la gobermentalidad ${ }^{2}$. Siguiendo a McKenzie (2001), se puede argumentar que este cambio implica

2 Esto es un conjunto de acciones organizadas que comprometen mentalidades, racionalidades y tecnologías, a través de las cuales una comunidad se hace gobernable (Foucault, 1991). En tal sentido, el principio de la performatividad se encontraría alineado con una manera particular de racionalizar y ejercer el gobierno, que Foucault (1997), identifica como propia del neoliberalismo y que según Lemke (2001: 191 ) busca darle viabilidad política a una situación en la que el Estado se reduce y los servicios de salud, educación y seguridad se privatizan. un desplazamiento de tecnologías disciplinarias y de vigilancia, que comprenden, por ejemplo, la organización del trabajo bajo principios científicos y racionales que producen burocracia centralizadas y jerarquizadas, hacia tecnologías performativas que involucran la organización del trabajo bajo principios participativos y persuasivos, regidas según los conceptos de responsabilidad, liderazgo, autogestión, y de donde emergen organizaciones descentralizadas y centradas en el actor. Se trata de tecnología cuya eficiencia se sustenta en la valoración de la diversidad, la innovación y la intuición del actor.

A tales tecnologías performativas corresponden, a su vez, formas de vigilancia y de evaluación del rendimiento y de la productividad, para lo cual existe una serie de procedimientos ad hoc, que incluyen desde las metodologías para el control de calidad de productos y servicios hasta dispositivos tecnológicos que se colocan en el propio cuerpo con el fin de establecer correlaciones entre presión arterial, ritmo cardíaco y productividad, estableciendo, a su vez, correlaciones entre rendimiento y desempeño físico y goce o insatisfacción. De este modo, el actor puede incluso evaluar su propio 
rendimiento a la vez que establecer nuevas metas y diseñar planes de acción en el futuro.

\section{La imagen y su función performativa}

Como ya he venido anotando líneas arriba, el modo en que se ha teorizado sobre la imagen ha estado dominado por enfoques representacionales. Así, por ejemplo, se distingue entre íconos, índices $y$ símbolos usando como criterio de clasificación la relación que guarda el signo con un objeto, con una realidad (Pierce, 1974). Sin embargo, en el complejo mundo de imágenes visuales en el que se está inmerso se pueden identificar aquellas que no tienen como fin representar alguna realidad en particular, sino que buscan más bien producir hechos. El ícono de los cubiertos nos señala que hay un sitio para comer, las aplicaciones en una pantalla de computador indican que hay programas a los que podemos recurrir, y el signo de prohibido estacionar nos conmina a seguir una indicación.

En otras palabras, lo que se busca, principalmente, es tener un efecto sobre la conducta. Se trata, pues, de signos que tienen una cualidad performativa en cuanto implican un compromiso con el entorno. El sentido último no es hacer referencia a una verdad. Por lo tanto, los signos en mención no están sujetos a juicio sobre su veracidad, sino sobre su eficacia. Al igual que un "acto de habla” (Austin, 1965, p. 55), el símbolo de no estacionar pone al receptor en una determinada circunstancia, $y$ en ese sentido realiza una acción. En este caso, se trata de una acción que solo puede ser respondida por otra acción: acatar la orden o seguir la indicación o no hacerlo.

Gran parte del paisaje urbano está plagado de signos que tienen por objeto regular el recorrido que se haga por él. Lo mismo hacen las aplicaciones que se encuentran en las pantallas del computador o en los iPhones. Estos guían, indican rutas posibles de transitar. Las aplicaciones, como Facebook, son otro ámbito en el cual se actúa a través de lo visual. El mundo de imágenes virtualizado de la era digital impone sobre los sujetos el mandato de participar, y se establecen, además, complejas conexiones con el mundo "real". Pero también el lenguaje publicitario hace amplio uso de una visualidad performativa.

Se trata de un mundo visual que compromete las subjetividades de 
una forma diferente, ya que nos convierte en agentes, que, a su vez, son evaluados respecto de sus respuestas efectivas, es decir, por su productividad y creatividad. Esta nueva subjetividad promueve como una forma de realización personal basada en la inmediatez y fugacidad de la presencia del hombre en el mundo. En ese sentido, reta el binomio sujeto/ objeto que dominó la modernidad, a la vez que se alinea con los modelos de autogestión y de responsabilidad de la persona que provoca el mandato de la participación.

Como se ve, el desarrollo de nuevas tecnologías y lenguajes en el orden actual requiere abordar el mundo de lo visual considerando la función performativa de las expresiones visuales. Este concepto guarda mayor coherencia con las nociones de conectividad, simultaneidad y redes que rigen el mundo de hoy. Mi argumento es que la visualidad en el mundo contemporáneo ya no se manifiesta a través de imágenes del mundo, sino a través de imágenes en el mundo. La función referencial, que como se ha visto para el contexto moderno es principalmente clasificatoria $y$, por ende, se encuentra vinculada al archivo, ha cedido lugar a la función performativa y, por tanto, a una creciente definición y uso de las expresiones visuales como repertorios que son puestos en acción en contextos específicos y de modo estratégico. Las expresiones visuales, por lo tanto, se evalúan por su eficiencia y eficacia, es decir su operacionalidad y no por su representatividad. Recordemos las imágenes antes vistas de la serie CSI-NY.

En la actualidad, la tecnología digital ha impactado en la portabilidad, intercambiabilidad, y replicabilidad de la imagen fotográfica. ¿Qué tipos de usos son posibles? ¿Cómo se instrumentalizan estos en términos de la creación de identidades, sentidos de pertenencia o la generación de relaciones sociales? ¿De qué manera impactan en la propia conceptualización o usos de la diferencia, en la forma en que opera la vigilancia o en el modo en que se redefinen las fronteras entre lo público y lo privado?

Para obtener una comprensión de la imagen en el mundo actual hay que situarla en este nuevo régimen y preguntarnos acerca de cómo opera con respecto a los mandatos de la performatividad y participación. La propuesta de ensayar nuevas aproximaciones teóricas que presten 
atención a la función performativa de la imagen al mismo tiempo significa replantearse los viejos problemas del poder, la agencia y la constitución de subjetividades.

Quisiera concluir -y solo con el afán de sugerir por dónde iría una posible agenda para la investigación de la imagen en el mundo de hoy- proponiendo que el estudio de la imagen en relación al mandato es la participación que debe darse al menos en un ámbito importante. Este ámbito es el de la seguridad. Una interrogante importante sería acerca del tipo de relación que están promoviendo las tecnologías de vigilancia y sus distintos usos entre Estado, ciudadano y sector privado. ¿Quiénes tienen capacidad de ejercer vigilancia en el mundo de hoy? ¿Qué significa que el ciudadano tenga un creciente acceso a las tecnologías de vigilancia y sea empoderado para participar y colaborar en la lucha contra la delincuencia, el pandillaje y el narcotráfico? ¿Qué paradojas encierra este tipo de empoderamiento en un contexto en el que se observa la privatización y reducción del Estado a la par de una creciente militarización? ¿Resulta ese empoderamiento funcional a un orden en el cual seguridad, pero también salud y educación son cada vez más la responsabilidad del individuo y que, por lo tanto, requiere de sujetos altamente participativos? Y si dejamos de participar o no contamos con los recursos para hacerlo, entonces... ¿estamos fuera?

¿En qué situación de poder se ubican aquellos grupos como las bandas de narcotraficantes que usan la red para publicitar sus acciones y que muestran un alto grado de desempeño en la web, precisamente cuando lo que otorga legitimidad al interior del sistema son criterios como los de la efectividad y eficacia? La lógica del sistema los avala, sobre todo si performan mejor que el ciudadano que se encuentra dentro de la ley.

Finalmente creo que el enfoque performativo nos abre también a la consideración de otros repertorios, no necesariamente visuales. En este mundo performativo, estos últimos más bien parecen estar perdiendo la primacía y exclusividad con la que contaban en la modernidad. Me parece de cuidado que el estudio de las dimensiones sensoriales de los repertorios performativos, así como de los otros sentidos, no sean una prioridad en la academia, mientras que, por ejemplo, en el marketing se 
observa un creciente uso del tacto, del olfato y de lo sonoro como mecanismos para generar lealtades de marca. El marketing, una disciplina hija de este mundo performativo, parece llevarse la delantera ante disciplinas académicas clásicas como las ciencias sociales y humanas. ¿Es que su alta performance es evidencia de que están entendiendo cómo funciona el mundo mejor que los científicos sociales? El régimen plantea también un reto a la academia, que debe re-pensar sus sentidos de verdad, de justicia y de ética a la luz de los nuevos términos en que se legitima el saber. ¿Cuál es el lugar de la reflexión crítica y ética que las disciplinas clásicas han ostentado?

\section{Referencias}

Austin, J. L. (1965). How to do things with words. Nueva York, Oxford University Press.

Cánepa, G. (2005). Imágenes públicas de la corrupción: objetivación, vigilancia y espectáculo en los vladivideos. En Ugarteche, Ó. (comp.). Vicios públicos: poder y corrupción (pp. 165-224). Lima: SUR Casa de Estudios del Socialismo.
Debord, G. (1976). La sociedad del espectáculo. Madrid: Miguel Castellote.

Faris, J. C. (1992). Anthropological transparency: film, representation, and politics. En Crawford, P. I. y Turton, D. (eds.). Film as ethnography (pp. 171-183). Mánchester: Manchester University Press.

Fiske, J. (1998). Videotech. En The visual culture reader (pp. 383-395) (ed. Mirzoeff, Nicholas). Londres: Routledge.

Flores, R. (en prensa). Etnografía visual y colonización cauchera. En La imagen como problema. Una mirada desde la antropología. Lima: Fondo Editorial de la PUCP.

Foucault, M. (1990). Vigilar y castigar: nacimiento de la prisión (trad. Aurelio Garzón del Camino). Madrid: Siglo XXI.

Foucault, M. (1991). Governmentality. En Burchell, G.; Gordon, C. y Miller, P. (eds.). The Foucault Effect. Studies in Governmentality (pp. 87104). Chicago: University of Chicago Press.

Heidegger, M. (1960). La época de la imagen del mundo. En Sendas 
perdidas (pp. 241-262). Buenos Aires: Losada.

Lemke, T. (2001). Participation. En Kulturkreis der deutschen Wirtschaft im Bundesverband der Deutschen Industrie e.V. (Hg.), Ars Viva 10/02 Kunst und Design, Berlín.

Lyotard, J. (1987). La condición posmoderna: informe sobre el saber. Madrid: Cátedra.

McKenzie, J. (2001). Perform or else, from discipline to performance. Londres: Routledge.

Mirzoeff, N. (1998). The visual culture reader. Londres: Routledge.

Pierce, C. (1974). La ciencia de la semiótica. Buenos Aires: Nueva Visión.

Poole, D. (2000). Visión, raza y modernidad. Una economía visual del mundo andino de imágenes. Lima: SUR Casa de Estudios del Socialismo.

Turner, T. (1991). Indigenous and culturalist movements in the contemporary global conjuncture. En Globalización, fronteras culturales $y$ política y ciudadanía. Actas del VIII Congreso de Antropología. Santiago de Compostela-Brasil: Federación de Asociaciones de Antropología del Estado Español-Asociación Galega de Antropoloxia.

Turner, T. (1996). El desafío de las imágenes: la apropiación Kayapó del video. En Globalización y cambios en la Amazonía indígena (ed. Fernando Santos Granero). Quito: Flacso-Abya-Yala. 
- Imágenes del mundo, imágenes en el mundo - Gisela Cánepa 